\title{
REFORMA PSIQUIÁTRICA, ECONOMIA SOLIDÁRIA E INCLUSÃO SOCIAL
}

\author{
Francisca Bezerra de Oliveira* \\ Ariadne Pereira Pedroza** \\ Evaldo Teles Rodrigues ${ }^{* * *}$ \\ Maria Ayrlles Macêdo**** \\ Thaís Kamilla Alves Pereira****
}

\section{RESUMO}

Este trabalho tem como objetivo refletir sobre os conceitos de Reforma Psiquiátrica, Economia Solidária e Inclusão Social. Busca-se mostrar a importância e a atualidade desses temas na construção de saberes e práticas no campo da saúde mental. As reflexões teórico-críticas deste ensaio estão respaldadas em autores que abordam a Reforma Psiquiátrica e a Economia Solidária. Procura-se construir um conhecimento que convide à busca, à reflexão e à construção de práticas inclusivas. Observa-se que a discussão desses temas possibilita aos profissionais do campo da saúde mental e demais áreas a constituição de práticas e fazeres fundamentados numa dimensão ética, social, inclusiva e acolhedora.

Palavras-chave: Saúde Mental. Reforma Psiquiátrica. Economia Solidária.

\section{INTRODUÇÃO}

As discussões que seguem são decorrentes de reflexões do nosso trabalho no campo acadêmico (projetos de extensão, de pesquisa, de ensino teórico-prático no campo da saúde mental) e da nossa participação efetiva nas discussões sobre o processo de Reforma Psiquiátrica no Brasil (conferências, mesas redondas, cursos, luta antimanicomial etc). São elaborações construídas em nosso cotidiano de trabalho, a partir de nossas inquietudes, e como possibilidades que vislumbramos de expor conceitos que possam compor instrumentos de base para o desafio de

\footnotetext{
*Francisca Bezerra de Oliveira - Enfermeira, Doutora. pela USP, Professora Associada IV da Unidade Acadêmica de Enfermagem do Centro de Formação de Professores da Universidade Federal de Campina Grande. E-mail: oliveirafb@uol.com.br

** Ariadne Pereira Pedroza - Enfermeira, Mestre pelo Programa de Pós-graduação em Enfermagem, da Universidade Federal da Paraíba (UFPB). Email: ariadne.pedroza@gmail.com

*** Evaldo Teles Rodrigues - Graduando em Medicina do Centro de Formação de Professores/UFCG. E-mail: evaldomeds@gmail.com

**** Maria Ayrlles Macêdo - Psicóloga, Estudante de Pós-Graduação Residência Integrada em Saúde da Escola de Saúde Pública do CE. E-mail: ayrllesmacedo@ hotamil.com

***** Thaís Kamilla Alves Pereira - Graduanda em Enfermagem do Centro de Formação de Professores/UFCG. E-mail: kamillatkap thais@ hotmail.com
} 
construir práticas em saúde mental que superem a lógica do isolamento e possibilitem cuidados respaldados na autonomia, cidadania e construção de novas subjetividades.

As reflexões teórico-críticas deste ensaio estão ancoradas também em autores que abordam a Reforma Psiquiátrica (AMARANTE, 2007, 2015; AMARANTE et al, 2014, 2015; YASUI, 2010; OLIVEIRA, 2002; OLIVEIRA et al, 2012, 2014, 2015), e a Economia Solidária (BRASIL, 2005; 2006, 2009; SINGER, 2002, 2005; MEDEIROS; MEDEIROS, 2007; CARVALHAES, 2008).

Iniciamos discutindo um tema que para nós se tornou fundamental para a compreensão dos saberes e fazeres no campo da saúde mental - o conceito de Reforma Psiquiátrica. A partir desse conceito, abordamos o tema da Economia Solidária procurando observar como esse conceito pode ser compreendido e quais as contribuições teóricas para a construção de práticas que possibilitem à Inclusão Social.

Trabalhar no campo da saúde mental exige de todos: competência, criatividade, compromisso, ousadia, paixão, ética e utopia, tanto na construção das práticas como dos saberes que as norteiam. É preciso superar preconceitos e representações que associam o "louco" como algo estranho, algo da ordem da periculosidade social, sendo necessário o seu isolamento no hospital manicomial. O primeiro passo é ver positividade na experiência da loucura e ter a compreensão de que é possível tratar a pessoa com sofrimento mental em serviços de base comunitária, tendo como âncora à atenção de qualidade, à liberdade, à cidadania e à inclusão social. É o que buscaremos fazer a seguir.

\section{REFORMA PSIQUIÁTRICA}

A Reforma Psiquiátrica surge no Brasil no final da década de 70, a partir do Movimento de Trabalhadores em Saúde Mental (MTSM), constituído por atores sociais diversificados: profissionais, estudantes, intelectuais, familiares, usuários, dentre outros. Este movimento social dá início efetivo à luta pelos direitos dos pacientes psiquiátricos, faz denúncias e críticas sobre a violência dos manicômios, a mercantilização da loucura, a supremacia da rede privada de assistência e ao paradigma psiquiátrico manicomial (AMARANTE, 2007, 2015; OLIVEIRA, 2002; OLIVEIRA et al, 2012).

Para estes autores a Reforma Psiquiátrica é um movimento social complexo, marcado por impasses, tensões, conflitos e desafios, tem como objetivo um conjunto de transformações de práticas, saberes, valores culturais e sociais, favorecendo a construção de novas modalidades de atenção em saúde mental. A partir desse movimento o usuário que era considerado um objeto, sem direito a voz, tornou-se um ator social importante, com pleno direito à cidadania, à autonomia, ao acolhimento e a uma atenção de qualidade, em serviços de base comunitária. 
Diversos eventos foram fundamentais para o processo de construção da Reforma Psiquiátrica no Brasil: o Movimento de Trabalhadores em Saúde Mental, o Movimento de Luta Antimanicomial e a criação do Sistema Único de Saúde (SUS) que foi instituído pela Constituição Federal de 1988. São princípios do SUS: o acesso universal público e gratuito, a integralidade das ações e a equidade da oferta de serviços, sendo a rede de atenção em saúde mental parte integrante desse sistema.

Além desses eventos, a realização de diversas Conferências Nacionais de Saúde Mental (CNSM) foram fundamentais nesse processo. A I CNSM realizada em 1987 criticou, de forma veemente, o modelo assistencial "hospitalocêntrico", considerado de alto custo, iatrogênico, ineficaz, segregador e violador dos direitos fundamentais; a II CNSM, realizada em 1992, tendo como resultado efetivo o compromisso da substituição progressiva dos leitos psiquiátricos por uma rede integrada de atenção à saúde mental.

Em continuidade, a III CNSM, realizada em 2001, teve como tema principal "Reorientação do Modelo Assistencial", e afirmou a necessidade da construção de um modelo de atenção em saúde mental substitutivo ao manicomial, pautado pela ética, amplo acesso, qualidade da atenção e controle social, conferindo ao CAPS o valor estratégico para essa mudança; em 2010, em Brasília, foi realizada a IV CNSM e Intersetorial, com tema central "Saúde Mental direito e compromisso de todos: consolidar avanços e enfrentar desafios", sendo um dos principais eixos discutidos os direitos humanos e a cidadania como desafio ético e intersetorial, subsidiando ainda mais a Política Nacional de Saúde Mental (BRASIL, 2010; OLIVEIRA et al, 2012).

É importante destacar também a Lei 10.216, que após 12 anos de tramitação, em 6 de abril de 2001 foi aprovada pelo Congresso Nacional e sancionada pelo Presidente da República. Embora o projeto original proposto pelo Deputado Federal Paulo Delgado tenha sido rejeitado, foi aceito um substitutivo que dispõe sobre a proteção e os direitos da pessoa com transtorno mental e redireciona o modelo assistencial em saúde mental, ficando conhecida como a Lei da Reforma Psiquiátrica Brasileira.

No Brasil, a Reforma Psiquiátrica tem possibilitado o surgimento de novos equipamentos de atenção em saúde mental e inclusão social. Há experiências inovadoras fundamentadas na perspectiva da clínica, da ética, da solidariedade, da cidadania, da produção de vida e invenção da saúde, como: Centro de Atenção Psicossocial (CAPS), Serviços Residenciais Terapêuticos (SRT), Leitos de Atenção Integral em Saúde Mental nos hospitais gerais e Centros de Convivência. Além disso, ocorreu a criação de novos instrumentos de Cooperativas e Associações de Usuários de Saúde Mental que procuram trabalhar na perspectiva da economia solidária (YASUI, 2010; OLIVEIRA et al, 2012).

Os CAPS são serviços abertos e comunitários do SUS, cuja função é prestar atendimento 
clínico em regime de atenção diária, promover a inserção social da pessoa com sofrimento mental, através de ações intersetoriais; regular a porta de entrada da rede de assistência em saúde mental na sua área de atuação e dar suporte à atenção mental na rede básica, organizando assim, a rede de atenção à pessoa com sofrimento mental nos municípios. Estes serviços devem ser substitutivos e não complementares ao hospital psiquiátrico e proporcionarem diversos atendimentos: medicamentoso, psicológico, oficinas terapêuticas, atividades de lazer, projetos de alfabetização, de geração de renda e trabalho, visitas domiciliares, favorecendo o exercício dos direitos civis, o fortalecimento das relações interpessoais e a inclusão social (BRASIL, 2010; YASUI, 2010; OLIVEIRA et al, 2012, 2014).

De acordo com estes autores, os serviços substitutivos devem procurar desenvolver ao máximo suas habilidades de atuar no território, ou seja, não apenas no espaço geográfico e sim serem capazes de desenvolver relações com os vários recursos existentes na sua comunidade. Devem se constituir como espaço de escuta, de acolhimento, de criação de vínculos, e de agenciamento de experiência subjetivas.

No processo de construção da Reforma Psiquiátrica, a partir de uma lógica comunitária de atenção à saúde mental, os CAPS devem oferecer recursos fundamentais para a reinserção social do sujeito em sofrimento mental de modo a promover a sua autonomia por meio do aumento do seu poder de contratualidade social. Trata-se de um processo que aumenta a capacidade do sujeito de estabelecer trocas sociais e afetivas nos diversos cenários: na família, no trabalho e na sociedade, resgatando assim, sua autonomia.

Caminhar na perspectiva da Reforma Psiquiátrica exige de todos nós o desejo de mudança. Nossa tarefa atual é sair dos limites confortáveis das verdades únicas que funcionam como ansiolítico. É inventar novas ideias, novas utopias, é não trair o passado daqueles que nos ajudaram a ser éticos - mais justos, libertários e solidários. Estamos nos referindo a pensadores como Karl Marx, Sigmund Freud, David Cooper, Ronald Laing, Michel Foucault, Félix Guattari, Erwing Goffman, Robert Castel, Roland Barthes, Franco Basaglia, Nise da Silveira e tantos outros teóricos humanamente éticos, que nunca deixaram de lutar por uma sociedade mais justa e inclusiva.

Nesse tipo de sociedade deve-se conviver com a diversidade, compreender que os saberes são sempre imprevisíveis e inacabados, e defender a verdade, a serviço da liberdade e da solidariedade, e ver que o "outro", inclusive o "louco", secularmente excluído, é outro de nós.

Questionamos: Como podemos pensar a Inclusão Social de pessoas secularmente excluídas da sociedade, como é o caso dos "loucos"? Como podemos trabalhar a atenção em saúde mental em um país que tem como projeto econômico o neoliberalismo que favorece a exclusão? De acordo com nossa concepção, constitui-se em um grande desafio, mas vale a pena sonhar e viabilizá-lo na prática cotidiana. Com dizia Shakespeare: “somos feitos da matéria dos sonhos”. Por que esquecer 
isto? A concretude da saúde como potência de vida alegre, começa pela potência dos sonhos.

É importante fazer referência à resposta de Freud, já idoso e no término de sua vida, a uma pergunta que lhe fizeram: Mestre, o que é ser normal? Com toda complexidade de sua obra e sua sabedoria, ele respondeu: "Ser normal é a pessoa que ama e que trabalha". Portanto, é sobre esse tema que iremos nos debruçar, inicialmente sobre Economia Solidária, logo em seguida, acerca da necessidade da intercessão Reforma Psiquiátrica e Economia Solidária, como possibilidade de Inclusão Social.

\section{ECONOMIA SOLIDÁRIA}

O trabalho sempre foi algo presente na vida cotidiana do homem, seja nas sociedades patriarcais, seja nas sociedades modernas. Foi por meio do trabalho que a sociedade humana se constituiu e determinou as formas de se relacionar com a natureza. A história da realização do ser social configura-se através da produção e reprodução de sua existência, ato social que se efetiva pelo trabalho. É, portanto, a partir do trabalho, que o homem torna-se ser social, estabelece relações de cooperação distinguindo-se de todas as formas não humanas de existência (CARVALHAES, 2008).

Historicamente, a partir do início da década de 1980, o Brasil ingressou na mais longa crise de desenvolvimento desde a $2^{\text {a }}$ Guerra Mundial, registrando um aumento significativo do número de trabalhadores expulsos do mercado formal de trabalho (BARFKNECHT; MERLO; NARDI, 2006).

Desde os primórdios da formação da sociedade capitalista, variados grupos sociais foram excluídos do mundo do trabalho, tornando o inacesso às ocupações remuneradas o traço mais marcante da exclusão social na pós-modernidade uma vez que, o não acesso à renda torna um indivíduo um "não sujeito" (TOMASI, 2008).

Diante da luta contra o aumento da pobreza e do desemprego, dois caminhos foram traçados: a ocupação informal (autônoma e individual) e iniciativas próprias, cooperativas, associações e outras formas produtivas do tipo familiar, até mesmo microempresarial, através de experiências econômicas de caráter solidário. Tais alternativas tornaram-se possibilidades concretas de geração de trabalho e renda (BARFKNECHT; MERLO; NARDI, 2006; TOMASI, 2008).

A economia solidária emerge na década de 90, como uma experiência econômica e como resposta dada pela sociedade e pelos trabalhadores a essa realidade, sendo organizada e orientada pelos princípios da autogestão, cooperação e solidariedade, predominando a igualdade entre seus membros, cujas modalidades de trabalho são socialmente justas. Rompe com a lógica capitalista cujos princípios são a competição, o individualismo e a dominância do capital sobre o trabalho. 
Pauta-se em um conjunto de valores e princípios que propiciam o bem estar das pessoas no trabalho no qual, todos têm poder de decisão e são responsáveis pelo empreendimento (MEDEIROS; MEDEIROS, 2007).

Em contraposição ao capitalismo centrado no desenvolvimento econômico e na lógica exclusiva de mercado, a economia solidária apresenta-se como alternativa ao desemprego e às relações empregatícias precarizadas, constituindo uma forma de trabalho por meio da inserção na sociedade, de exercício de cidadania, autonomia e democratização. Sua proposta é fundamentada nos autores clássicos, ou segundo o professor Paul Singer, socialistas utópicos: Owen, Fourier, Saint-Simon, dentre outros (MEDEIROS; MEDEIROS, 2007; SILVA; OLIVEIRA; BERTANI, 2007). Assim, a economia solidária

É antes de qualquer coisa, uma opção ética, política e ideológica, que se torna prática quando os optantes encontram os de fato excluídos e juntos constroem empreendimentos produtivos, rede de trocas, instituições financeiras, escolas, entidades representativas, etc., que apontam para uma sociedade marcada pela solidariedade, da qual ninguém é excluído contra a vontade (SINGER, 2005, p. 11).

O Movimento da Economia Solidária no Brasil tem como marco histórico de sua organização o encontro realizado em 2000, na cidade de Mendes no Rio de Janeiro, síntese dos encontros nacionais e internacionais entre os anos de 1988 e 1998 sobre experiências de economia popular e autogestão, com a participação de vários países latino-americanos e europeus, cooperativas, associações, sindicatos, instituições de desenvolvimento, constituindo o grande passo para a criação do Grupo de Trabalho Brasileiro de Economia Solidária realizado em 2001 na cidade de Porto Alegre, durante o Fórum Social Mundial (FSM) (ANDRADE et al, 2008).

Segundo estes autores, para que fosse reconhecido o espaço de oportunidades da economia solidária, foi realizada em 2002, na cidade de São Paulo, a I Plenária Nacional da Economia Solidária, na qual foi elaborada a "Carta ao Governo Lula", propondo a criação da Secretaria Nacional de Economia Solidária, o que veio a acontecer em 2003, tornando essa economia fortalecida e divulgada, mediante políticas públicas integradas; a II Plenária Nacional da Economia Solidária ocorreu durante o III FSM em 2003 na cidade de Porto Alegre, cuja proposta foi a criação do Fórum Brasileiro de Economia Solidária, mais tarde sendo deliberado e criado durante a III Plenária Nacional da Economia Solidária, realizada em 2003, em Brasília, composto por trabalhadores, empreendedores da economia solidária no país, agências de fomento, de pesquisa, de incubação, de assessoria e de gestores públicos.

Assim, diante da "flexibilização", a redução dos salários e a instabilidade dos empregos, a economia solidária vem crescendo como alternativa, recuperando o "valor atribuído à democracia e à igualdade dentro dos empreendimentos, a instância na autogestão e o repúdio ao assalariamento" (SINGER, 2002, p.111). 
O termo sócioeconomia procura dar conta de aspectos mais abrangentes, objetivando ressaltarem o objetivo principal da economia solidária, que se traduz em uma economia a serviço do ser humano, com valorização dos laços afetivos, de solidariedade e de amizade. Essas formulações partem de um ideário comum que as pessoas "vistam” a camisa da economia solidária.

\section{REFORMA PSIQUIÁTRICA E INCLUSÃO SOCIAL: ARTICULAÇÃO COM A ECONOMIA SOLIDÁRIA}

Um dos principais dispositivos da Reforma Psiquiátrica é a potencialização do trabalho como instrumento de inclusão social dos usuários do serviço e a ampliação do acesso à renda que tem sido uma das propostas do Governo Federal, especialmente no que se refere às populações que se encontram em desvantagem social, através da parceria da Secretaria Nacional de Economia Solidária, do Ministério do Trabalho e Emprego, com a Coordenação Nacional de Saúde Mental/DAPE/SAS/MS, do Ministério da Saúde (MARTINS, 2007; BRASIL, 2009).

A primeira experiência de cooperativa com a inclusão de usuários com sofrimento mental foi criada na década de 1970, no manicômio de San Giovanni. O objetivo da Cooperativa Lavoratori Uniti era a valorização do trabalho das pessoas internadas, composta de ex-internos, hóspedes e trabalhadores da cidade. Foi juridicamente reconhecida em 1974, passando a desenvolver serviços de limpeza dentro do hospital (NICÁCIO; MANGIA; GHIRARDI, 2005).

A partir da década de 80 , as cooperativas sociais se expandiram e fortaleceram, porém, no cenário nacional, na década de 90 a discussão ainda era restrita, sendo mais tarde, em 1994, proposto um projeto de lei para a criação das cooperativas para a regulamentação e inserção de pessoas em situação de desvantagem no mercado de trabalho, como os "deficientes" mentais, físicos e sensoriais, dependentes químicos, egressos de sistema prisional, idosos de suporte social restrito, adolescentes, entre outros. Este projeto tramitou no Congresso Nacional, sendo alterado e promulgado em 1999 ( GHIRARDI; NICÁCIO; MANGIA, 2005).

Em 2004 foi realizado o primeiro encontro Nacional de Centros de Atenção Psicossocial (CAPS) e a promoção conjunta, pelos Ministérios da Saúde e do Trabalho e Emprego, da primeira Oficina Nacional de Experiências de Geração de Renda de Usuários de Saúde Mental. Naquela oportunidade, foram identificadas 156 iniciativas de geração de renda formadas por pessoas em sofrimento mental, entre cooperativas, associações e grupos de trabalho, sendo Pelotas o primeiro município a encaminhar o projeto e receber o incentivo para organizar e implementar uma Oficina de Papel Reciclado.

Nesse sentido, isso demonstra que apesar de diferentes e de frágil sustentação financeira, estas experiências produzem autonomia e inclusão social e nascem, em sua maioria, dentro dos 
CAPS e nos Centros de Convivência e Cultura. Dentre as deliberações desta Oficina destacam-se a criação de um grupo de discussão nacional sobre o tema, bem como a instituição de um Grupo de Trabalho Interministerial (GTI), publicado pela Portaria Interministerial n ${ }^{0} 353 / 2005$ e composto por pessoas dos dois movimentos, para a construção e implementação dessa política, dando início ao Projeto de inclusão Social pelo Trabalho em Saúde Mental (BRASIL, 2005, 2006).

Para que o plano de reabilitação dos usuários da rede de saúde mental possa de fato se efetivar por meio da articulação Saúde Mental e Economia Solidária, o GTI se estrutura em quatro eixos: mapeamento de iniciativas de geração de renda em saúde mental e cadastro no Sistema Nacional de Informações em Economia Solidária , assim como sua atualização no Cadastro de Iniciativas de Inclusão Social pelo Trabalho, promovendo parcerias e articulações através da comercialização e da produção; formação, capacitação, assessoria e incubagem em pontos que precisam de investimentos para o fortalecimento dos empreendimentos; financiamento, subsidiado pela Portaria 1169/2005, destinando incentivo financeiro para os municípios que se habilitarem junto ao Ministério da Saúde para o desenvolvimento de atividades de inclusão social pelo trabalho; e o quarto eixo é a problematização da legislação neste campo, como a perda e os benefícios sociais, como a aposentadoria por invalidez e a forma jurídica dada aos empreendimentos da saúde mental, já que a clientela é vista pela lei como incapaz e inválida (BRASIL, 2006; MARTINS, 2007).

Desse modo, as oficinas de geração de renda, a inclusão pelo trabalho, as cooperativas norteadas pela economia solidária são componentes fundamentais no processo de construção da Reforma Psiquiátrica. Deve existir, portanto, uma interconexão entre as políticas públicas da Reforma Psiquiátrica e da Economia Solidária. O importante é que ambas "têm como princípios comuns um outro projeto de sociedade que seja inclusiva, ética, humanizadora, justa, solidária e alternativa ao modo de produção capitalista" (ANDRADE et al, 2008).

No caso da pessoa com sofrimento mental, secularmente excluída, pensar na geração de renda por meio da economia solidária implica trabalhar a reabilitação psicossocial, a inclusão social, a busca pela independência financeira e sua relação com as redes múltiplas de pertencimento.

Outro aspecto a ser destacado no que diz respeito à articulação entre saúde mental e economia solidária é a incubagem de empreendimentos econômicos solidários por meio de incubadoras universitárias (ou por ONGs e algumas prefeituras), que consistem basicamente no levantamento sobre as necessidades, potencialidades e expectativas do empreendimento, bem como métodos de atividades econômicas possíveis de serem desenvolvidas, análise da viabilidade do empreendimento, elaboração do plano de negócios, discussão sobre organização formal, acompanhamento psicossocial, administrativo, contábil e jurídico e, por fim, o processo de 
desincubagem (ANDRADE et al, 2008).

O Programa Nacional de Incubadoras de Cooperativas (PRONINC) tem como objetivo apoiar e desenvolver as experiências de Incubadoras Tecnológicas de Cooperativas Populares (ITCP), através da disponibilização de recursos provenientes tanto do Ministério do Trabalho e Emprego e do Ministério da Saúde. Duas estratégias foram de grande importância para o fortalecimento do programa: a primeira foi o envio do ofício circular $n^{\circ}$ 015/2005 do Ministério da Saúde às Incubadoras, citando a experiência pioneira do acompanhamento de quase 10 anos da COPPE/UFRJ à Cooperativa da Praia Vermelha, e propondo o estabelecimento de parcerias com projetos de incubagem envolvendo pessoas com transtornos mentais e/ou decorrentes do uso de álcool e outras drogas, sugerindo também a inclusão destas iniciativas nos planos de trabalho das incubadoras; a segunda foi o lançamento do edital do PRONINC - Modalidade B em 2007, definindo que na inclusão de novos empreendimentos a serem apoiados, deveriam ser preferencialmente incorporados, dentre outros, aqueles constituídos por usuários dos serviços de saúde mental, álcool e outras drogas (BRASIL, 2006; ANDRADE et al, 2008).

Em relação à experiência na Paraíba, a Incubadora de Empreendimentos Sócio-Econômicos Solidários (IUEES) da Universidade Federal de Campina Grande (UFCG) foi criada em 2008, na cidade de Campina Grande/PB, inicialmente, procurava assistir a duas comunidades que fazem parte do citado município, os catadores de lixo e os agricultores do distrito de São José da Mata, e uma comunidade na cidade de Cajazeiras, o Centro de Atenção Psicossocial (CAPS II). É apoiada e financiada com recursos da Secretaria de Estado da Ciência e Tecnologia e do Meio Ambiente (SECTMA) e pela Fundação de Apoio a Pesquisa do Estado da Paraíba (FAPESQ).

Entre maio de 2009 a dezembro de 2010, foi desenvolvido no CAPS do município de Cajazeiras - PB, o Projeto de Extensão vinculado ao Programa de Bolsa de Extensão (PROBEX)/UFCG, intitulado: "Capacitação de Usuários do Centro de Atenção Psicossocial de Cajazeiras - PB (CAPS II) para Produção de Artefatos Artesanais", sendo acompanhado sistematicamente e com um certo apoio financeiro da IUEES/UFCG. Tinha como objetivo principal promover a inclusão social de usuários do CAPS II de Cajazeiras - PB, por meio de sensibilização e capacitação, favorecendo o desenvolvimento de habilidades na produção de cartões artesanais, marcadores de livros, bolsas e pastas artesanais, produzidos a partir de materiais recicláveis, objetivando a geração de renda, a autonomia e a melhoria de vida dos usuários (PEDROZA et al, 2012).

De acordo com os autores, durante a realização do projeto de extensão foram desenvolvidas com 15 usuários as seguintes atividades: apresentação do projeto aos usuários e profissionais do CAPS; realização de palestras sobre educação em saúde e prevenção de doenças, higiene pessoal, 
do lar, cuidados com o meio ambiente e cooperativismo/associativismo, em parceria com a Secretaria Municipal de Cidadania e Promoção Social; capacitação dos usuários através de oficinas de geração de renda e trabalho na perspectiva da Economia Solidária promovida pela IUEES; e realização de oficinas de fabricação e confecção de papel reciclado e oficina de cadernos e bolsas artesanais.

A equipe executora também participou de cursos de capacitação sobre Economia Solidária durante toda a vigência do projeto; bem como de discussões sobre Saúde Mental e Economia Solidária no programa "UFCG nas ondas do Rádio"; participação e envio do projeto para a I Chamada de Projetos sobre Arte, Cultura e Renda na Rede de Saúde Mental do Ministério da Saúde; participação na I Oficina de Economia Solidária realizada em Cajazeiras - PB, e na Feira de Eventos "Praça da Gente" com os usuários do CAPS, na oportunidade foram apresentados os trabalhos elaborados pelos mesmos; organização de uma tenda no calçadão da Prefeitura Municipal de Cajazeiras, para venda dos cartões de Natal e bolsas artesanais, com a presença dos usuários. Realizamos também um encontro com a presença dos membros da IUEES/UFCG, a equipe do Projeto de Extensão, os usuários e os profissionais do CAPS, no Centro de Formação de Professores (CFP/UFCG), dirigido à comunidade universitária e à sociedade civil (PEDROZA et al, 2012).

Dessa experiência, constatamos que a formação inicial de empreendimentos solidários é ainda frágil e precisa de apoio constante até sua emancipação, uma vez que, o mercado de trabalho é competitivo e desigual. No caso dos usuários do CAPS, a desvantagem é ainda maior, devido às limitações decorrentes da doença, da baixa autoestima, além da resistência da família pelo medo que o usuário perca o benefício "auxílio-doença".

\section{CONSIDERAÇÕES FINAIS}

Entendemos que o propósito primordial dos profissionais que trabalham no CAPS deve ser a busca de superar barreiras sociais e culturais tão presentes na vida cotidiana da pessoa em sofrimento mental. É preciso valorizar e estimular a criatividade, a dança, a música e a capacidade de trabalho no mercado realizada por usuários de saúde mental.

Ainda existe um longo caminho a ser percorrido, uma vez que o "louco" esteve sempre tutelado, institucionalizado e marginalizado. É possível pensar um outro locus para o usuário do CAPS, ver positividade na experiência da loucura, possibilitando trocas sociais, afetivas e agenciamento de novas experiências subjetivas. As novas práticas em saúde mental devem ser construídas baseadas, não em verdades científicas, mas em função de suas eficiências ético-estéticoexistenciais.

Trabalhar na perspectiva da Reforma Psiquiátrica e da Economia Solidária, objetivando a 
Inclusão Social de usuários de saúde mental exige de todos nós compromisso, competência, ética e utopia. Só assim o trabalho solidário pode se constituir como um instrumento valioso, um recurso terapêutico e uma estratégia de geração de renda, autonomia e legitimação da cidadania do usuário.

\section{REFERÊNCIAS}

AMARANTE, P. Saúde mental e atenção psicossocial. Rio de Janeiro: Fiocruz, 2007.

. Loucos pela vida: a trajetória da Reforma Psiquiátrica no Brasil. Rio de Janeiro:

FIOCRUZ, 2015.

AMARAnTE, P. (Org.). Psiquiatria Social e Reforma Psiquiátrica. Rio de Janeiro: FIOCRUZ, 2014.

ANDRADE, M. C. et al. Saúde Mental e Economia Solidária - Relato de Experiência de um Projeto de Inclusão Social pelo Trabalho. IV NESOL - USP, 2008. Disponível em: < http://www.unitrabalho.uem.br/artigos/pdf9.pdf>. Acesso em: 10 set de 2015.

BARFKNECHT, K. S.; MERLO, A. R. C.; NARDI, H. C. Saúde Mental e Economia Solidária: Análise das relações de trabalho em uma cooperativa de confecção de Porto Alegre. Psicologia \& Sociedade; vol.2. n.18: p. 54-61; mai./ago. 2006. Disponível em: < http://www.scielo.br/pdf/psoc/v18n2/07.pdf >. Acesso em 09 Set 2015.

BRASIL. Ministério da Saúde. Conselho de Saúde. Conferência Nacional de Saúde Mental Intersetorial: CNS aprova Recomendação sobre a realização de conferências regionais e os subeixos. Brasília: 2010. Disponível em: <conselho.saude.gov.br/../2010/12_mar_saude_mental.htm>. Acesso em 01 Set 2015.

. MINISTÉRIO DA SAÚDE. Saúde Mental. CAPS. Brasília: 2009. Disponível

em<http://portal.saude.gov.br/portal/saude/visualizar_texto.cfm?idtxt=29797\&janela=1> Acesso em 10 Jun 2015.

. MINISTÉRIO DA SAÚDE. Saúde mental em dados 5 - ano III, nº5. Informativo eletrônico. Brasília, 22p. 2008. Disponível em<http://www.ccs.saude.gov.br/saude_mental/pdf/smDados/2008_SMD_05.pdf> Acesso em 01 Mai 2015.

. MINISTÉRIO DA SAÚDE. Secretaria de Atenção à Saúde. DAPE. Coordenação de Saúde Mental. Ministério do trabalho e Emprego. Secretaria Nacional de Economia Solidária. Relatório Final do Grupo de Trabalho Saúde Mental e Economia Solidária. Portaria Interministerial $n^{\circ}$ 3531, 2006. Disponível em: <http://www.saude.gov.br.>. Acesso em 11 Jun 2015.

. MINISTÉRIO DA SAÚDE. Secretaria de Atenção à Saúde. DAPE. Coordenação Geral de Saúde Mental. Reforma psiquiátrica e política de saúde mental no Brasil. Documento apresentado à Conferência Regional de Reforma dos Serviços de Saúde Mental: 15 anos depois de Caracas. OPAS. Brasília: Ministério da Saúde, 2005.

CARVALHAES, A. G. O lugar do trabalho solidário na Reforma Psiquiátrica Brasileira. 109f. Dissertação Mestrado,- Filosofia e Ciências Humanas, Universidade Federal de Minas Gerais,2008. 
MEDEIROS, A. D. de. MEDEIROS, A. C. D. de. Relações de trabalho na economia solidária: novas formas de pensar e agir. 2007. Disponível em:

http://www.asbraer.org.br/Documentos/Biblioteca/rela\%C3\%A7\%C3\%A3o\%20de\%20trabalho\%2 0na\%20economia\%20solid\%C3\%A1ria.pdf >. Acesso em 20 Jun 2015.

MARTINS, R. C. A. Saúde Mental e Economia Solidária: Inclusão Social pelo Trabalho. Área temática: Trabalho na Sociedade Contemporânea. Coordenação Nacional de Saúde Mental.

Departamento de Ações Programáticas e Estratégicas. Secretaria de Atenção à Saúde. Ministério da Saúde. 2007. Disponível em: < http://www.poli.usp.br/p/augusto.neiva/nesol/Publicacoes/Anais\%20\%20Grava\%C3\%A7\%C3\%A3o/arquivos\%20III\%20Encontro/Tra-1.htm>. Acesso em 10 Out 2014.

NICÁCIO, F.; MANGIA, E. F.; GHIRARDI, M. I. G. Projetos de inclusão no trabalho e emancipação de pessoas em situação de desvantagem: uma discussão de perspectivas. Revista de Terapia Ocupacional da Universidade de São Paulo. São Paulo. v.16 n.2 São Paulo mai/ago. 2005. Disponível em: http://www.revistasusp.sibi.usp.br/scielo.php?pid=S1415$1042005000200003 \&$ script=sci_arttext $>$. Acesso em 12 Set 2015.

OLIVEIRA, F. B. de. Construindo saberes e práticas em saúde mental. João Pessoa: Editora Universitária/UFPB, 2002.

OLIVEIRA, F. B. de. et al. Saúde mental no contexto da saúde da família. In: OLIVEIRA, F. B. de; LIMA JÚNIOR, J. F.; MOREIRA, M. R. C. Resgatando saberes e ressignificando práticas: interfaces no campo da saúde coletiva. 1 ed. Campina Grande, PB: EdUFCG, 2012. p. 81-97.

OLIVEIRA, F. B. de. et al. Reconstruindo novos paradigmas do cuidado em saúde mental na estratégia saúde da família. Rev Enferm UFPE on line., Recife, 8(4): 919-26, abr., 2014.

OLIVEIRA, F. B. de. et al. Music and dance expressions circles with mental health users: an experience report. MedPuh Journals. Internacional Archives of Medicine, vol. 8. no. 192, p. 1-7., 2015.

YASUI, S. Rupturas e encontros: desafios da Reforma Psiquiátrica Brasileira. Rio de Janeiro: Fio Cruz, 2010.

PEDROZA, A. P. et al. Articulação saúde mental e economia solidária: relato de projeto de inclusão social. Rev Rene. 2012; 13(2):454-62.

SILVA, E. P. da; OLIVEIRA, T. M. de; BERTANI, I. F. Saúde Mental e Economia Solidária: uma relação em construção. ENCONTRO INTERNACIONAL DE ECONOMIA SOLIDÁRIA. O DISCURSO E A PRÁTICA DA ECONOMIA SOLIDÁRIA.5., NES. USP. São Paulo, 2007.

Disponível em:

<http://www.poli.usp.br/p/augusto.neiva/nesol/Publicacoes/V\%20Encontro/Artigos/Diversidade/DI -02.pdf $>$. Acesso em 11 Set 2015.

SINGER, P. Introdução à economia solidária. São Paulo: Fundação Perseu Abano, 2002.

BRASIL. Saúde Mental e Economia Solidária. In: Brasil, Ministério da Saúde. Secretaria de Atenção à Saúde. Departamento de Ações Programáticas Estratégicas. Saúde Mental e Economia Solidária: inclusão social pelo trabalho. Brasília: Ministério da Saúde, 2005.

TOMASI, E. Saúde Mental, trabalho e economia solidária em Centros de Atenção Psicossocial - CAPS. Escola de Psicologia - UCPEL - Pelotas, RS, 2008. Disponível em: <

www.capspelotas.com.br/projeto/projeto-saude-trabalho.pdf $>$. Acesso em 17 Set 2015. 